\title{
Back to the clinic: without a rationale there is no worthy
} research question

\author{
Juan O. Talavera, ${ }^{1 *}$ Rodolfo Rivas-Ruiz, ${ }^{2}$ Marcela Pérez-Rodríguez, ${ }^{2}$ Ivonne Analí Roy-Garcia ${ }^{2}$ and \\ Lino Palacios-Cruz ${ }^{3}$ \\ ${ }^{1} T e a c h i n g$ and Research Directorate, Centro Médico ABC; ${ }^{2}$ Instituto Mexicano del Seguro Social, Coordination of Health Research, Centro Médico \\ Nacional Siglo XXI, Clinical Research Training Center; ${ }^{3}$ Secretaría de Salud, Instituto Nacional de Psiquiatría "Dr. Ramón de la Fuente", Clinical \\ Research Sub-directorate, Department of Clinical Epidemiology. Ciudad de México, Mexico
}

\begin{abstract}
A clinical research question requires the concurrence of clinical experience and knowledge on methodology and statistics in that who formulates it. Initially, a research question should have a structure that clearly establishes what is that which is being sought (consequence or outcome), in whom (baseline status), and by action of what (maneuver). Subsequently, its reasoning must explore four aspects: feasibility and reasonableness of the questioning, lack of a prior answer, relevance of the answer to be obtained, and applicability. Once these aspects are satisfactorily covered, the question can be regarded as being "clinically relevant", which is different from being statistically significant, which refers to the probability of the result being driven by chance, which does not reflect the relevance of the question or the outcome. One should never forget that every maneuver entails adverse events that, when serious, discredit good results. It is imperative to have the possible answer estimated from within the structure of the question. The function of clinical research is to corroborate or reject a hypothesis, rather than to empirically test to find out what the outcome is.
\end{abstract}

KEY WORDS: Justification. Clinical research question. Relevance.

An ignorant knows more when asking, than a wise person when answering.

Without a question there is no answer, and without a rationale there is no answer that is worth.

POPULAR SAYINGS

\section{Introduction}

A relevant clinical research question is that which seeks to improve patient health or quality of life. To make it available, it will be necessary to have a structurally justified questioning.
If the rationale that gives rise to the question is not adequate, great effort will be invested with minimal benefits for patients and, even worse, many people will occasionally be exposed to unjustified procedures or maneuvers.

The generation, publication and inappropriate use of information that answers an unjustified question is undoubtedly a responsibility that is shared by several stakeholders:

- Researchers, who in many cases start a project where they ignore the magnitude and applicability of the expected benefit or, even worse,
Date of reception: 21-12-2018

Date of acceptance: 16-01-2019

DOI: 10.24875/GMM.M19000250
Gac Med Mex. 2019;155:154-160

Contents available at PubMed www.gacetamedicademexico.com 
sometimes since the planning of the study, they foresee minimal benefit or inapplicability of the result and deliberately ignore it owing to a conflict of interests unrelated to patient or population well-being. In addition to this, once they have the results, and taking advantage of statistical significance (which is not synonymous with clinical relevance), they conclude that the maneuver is useful, even when the benefit in clinical practice is marginal or associated with high costs and adverse events that exceed the benefit. ${ }^{1-4}$

- Ethics and research committees, which approve the execution of projects only based on compliance with ethical and scientific requirements, without assessing the social value ${ }^{5}$ or responsible use of resources, which are always finite. ${ }^{6}$

- Publications' editorial committees, which allow the publication of reports with tendentious language and unjustified or magnified conclusions. ${ }^{7,8}$

- Doctors and health authorities in the community, who make indiscriminate use of recommendations only because of their statistical significance, without reflecting on the expected real benefit and, in some cases, even adding them to simplified clinical practice guidelines, which indirectly promote acritical "information consumption". ${ }^{9}$

This is how all participants, from the generation of a research proposal to the use of the results, have the obligation to possess knowledge and experience on the subject of interest -preferably being health professionals with clinical experience- and a minimum knowledge of methodology and statistics, which are topics discussed in 24 articles of a series entitled "Clinical research", published from 2011 to 2014 in Revista Médica del Instituto Mexicano del Seguro Social, ${ }^{10,11}$ where offering physicians an instrument to understand how the information they use in the care they provide day by day to their patients is generated and interpreted, as well as to guide their activities in clinical research, was sought.

If we consider the concurrence of clinical experience with basic knowledge of methodology and statistics, then the relevance of the research question, which is generated by the combination of systematized observation during the practice of medicine and a gap in knowledge, can be judged. If the question is not based on both these elements, there is the risk of having an unjustified question and, consequently, an irrelevant answer, no matter how sophisticated the methodological design or statistical analysis are, or how much money is invested. ${ }^{12}$

\section{Research question rationale (Table 1)}

Initially, the research question should have a structure that makes clear what is it that is sought (the outcome or expected consequence), in whom (baseline status) and by action of what (the maneuver); ${ }^{10,13,14}$ this architectural research design for causality studies was described by Alvan R. Feinstein ${ }^{14}$ and constitutes a detailed description of the clinical activities every physician in the area of care are familiar with. An example of a clinical question would be the following: in a patient with type 2 diabetes mellitus with overweight-obesity (baseline status), will weight reduction (experimental maneuver) be more relevant than strict pharmacological glucose control (comparative maneuver) to prevent macro or microvascular damage (outcome)?

Once the components of the question are clear baseline status, maneuver and outcome-, the rationale behind them forces to explore the feasibility and reasonableness of the question generated by observation,,$^{15}$ the lack of a previous answer,,$^{13,16}$ the relevance of the possible answer to be obtained ${ }^{5,17}$ and its applicability. ${ }^{15}$

\section{Feasibility and reasonableness of the question generated based on an observation}

a) Does the action of the maneuver (observational, by exposure to a risk or protective factor, or experimental, by assignment by the researcher) on the baseline state have a biological explanation ${ }^{18}$ or an epidemiological basis? It is not always possible to explain the biological mechanisms by means of which a causal relationship is observed, since it depends on available knowledge. Example: at the end of the $19^{\text {th }}$ century, Rigoni Stern (1842) analyzed data of the death certificates of women with cervical cancer; he observed a high frequency of married women, widows and prostitutes, and very low frequency of nubile women and nuns. He concluded that the development of this cancer could be associated with sexual contact, an observation that was the precedent of what now we know about the role of human papilloma virus in the development of cervical cancer. ${ }^{19}$

b) The explanation by means of which the probable action of the maneuver is justified, is it logical? Example: the mechanism by means of which human papilloma virus infection is associated with the development of cervical cancer, among other reasons, is 


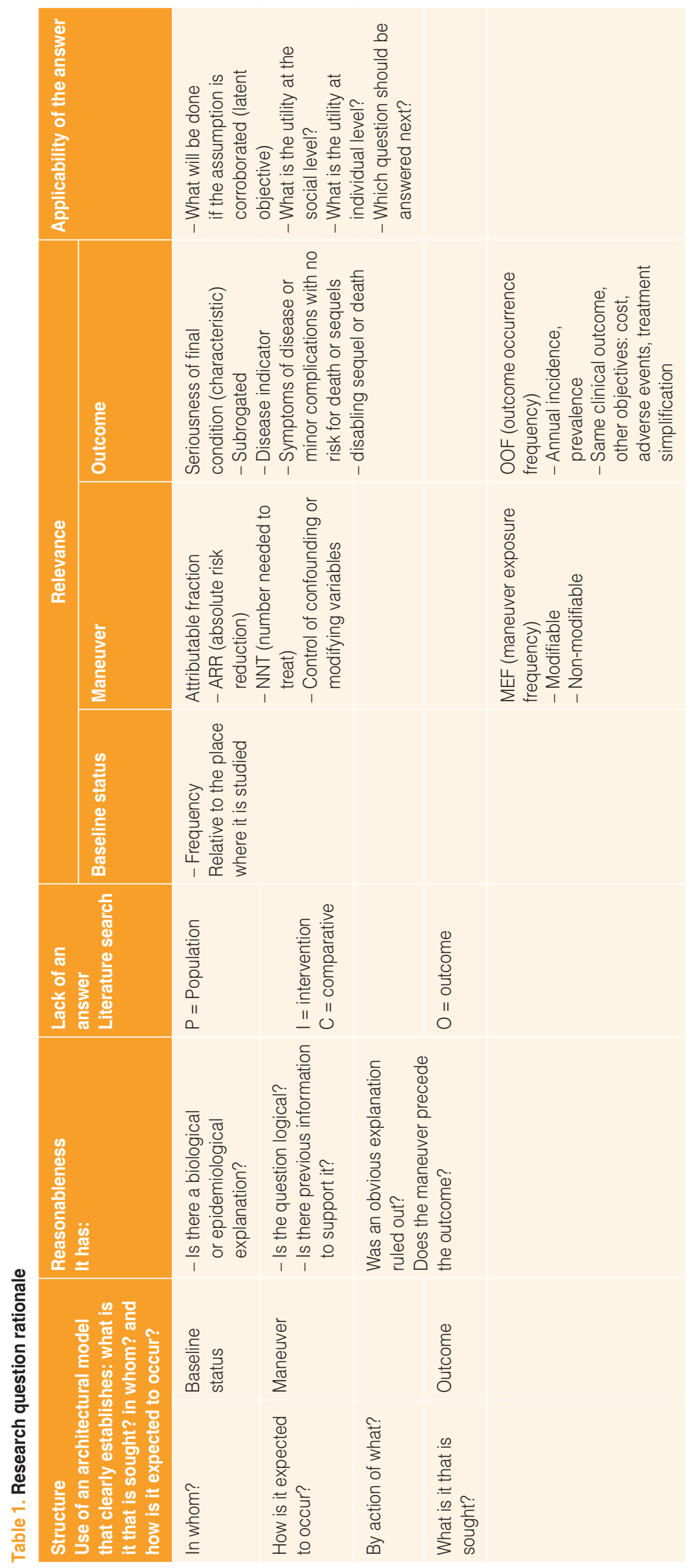


explained by viral proteins E6, E7 and pRb, which cause cell perpetuation through tumor suppressor p53 inactivation. This and other mechanisms cause a proliferation of cells with reduced capacity to repair mutations, which ultimately leads to the development of cancer. ${ }^{20}$

c) Do the observations that give rise to the question stem from direct and justified evidence and not from an assumption or not-yet-validated information? In that case, a second assumption would not be justified. Example: after the influenza epidemic in 2009, studies were published where obesity was proposed as a risk factor for the development of complications and mortality. Even when the consistency of these results had not been demonstrated, investigations were carried out to find the pathophysiological mechanisms that would explain this supposed association. ${ }^{21}$ Later, when adjustments were made for the presence of other comorbidities, the effect of obesity was shown to be lost. ${ }^{22}$

d) Has the existence of an obvious alternative explanation, independent of the maneuver of interest, been ruled out? Example: In 2009, an article was published in Nature evaluating the effect of room lighting in children younger than two years and its association with the development of myopia. Children who slept with the light on had a higher prevalence of myopia (48\%) than those who slept with the light off $(9 \%) .{ }^{23}$ In 2010, other researchers found different results; they attributed the difference to the failure to measure a third variable: parental history of myopia, which is why the light in the room was kept on. ${ }^{24}$

e) Does the maneuver precede the outcome? That is, is the action of the maneuver on the basal state always observed to precede the effect or outcome? Bradford Hill stated that this is particularly relevant in slowly developing diseases and exemplified it with the following questions: can a particular diet lead to the development of " $X$ " disease or is it that early stages of the disease elicit peculiar dietary habits? or does any occupation in particular promote infection with the tuberculosis bacillus, or is it that men and women who select this type of occupation are more prone to contract tuberculosis, or is it that, in fact, they had already contracted the disease? ${ }^{18}$

\section{Lack of a previous answer}

The lack of a previous answer should be confirmed through a systematic search using the term PICO, an acronym based on the three components of the question: baseline state ( $P=$ population), maneuver ( $\mathrm{I}=$ intervention, $\mathrm{C}=$ comparative maneuver) and outcome $\left(\mathrm{O}=\right.$ outcome) ${ }_{13}^{13}$ which does not mean there is a lack of previous studies on the subject; in fact, the research seeks to solve a need by corroborating a perfectly documented hypothesis. However, care must be taken not to repeat a research project with a question that has already been answered. Example: Fergusson et al. conducted a systematic review to assess the efficacy of aprotonin in the reduction of perioperative bleeding. Of 64 clinical trials found, all indicated that it was a protective factor; only $20 \%$ referred previous studies. This shows a large number of clinical trials to assess an already proven efficacy and the lack of reference to studies that had previously demonstrated it. ${ }^{25}$

\section{Relevance of the possible answer}

A research has been regarded as not having social or scientific value when the knowledge that is tried to be generated does not contribute to understanding or solving a health problem. ${ }^{26}$ Thus, we will refer to the relevance of the research question from the perspective of the three components of the architectural model:

a) Relevance of the baseline state. The importance should be considered by weighing the frequency, which depends on whether this is made since the moment of decision-making at the government level or within the health system, or in the setting of a hospital or in the office. In the first case, this is important in pathologies or conditions of high prevalence or incidence (such as diabetes mellitus, the prevalence of which is $9.4 \%) ;{ }^{27}$ in turn, rare diseases can be of interest in referral centers. An example: multiple sclerosis has a prevalence of 33 cases per 100,000 population in Mexico, which would not justify its study in the general population; however, it may be relevant in a specialty hospital where there is a registry of several hundreds of patients. ${ }^{28}$

b) Relevance of the outcome. Important characteristics include:

- Frequency of the outcome. The more frequent an unfavorable outcome is, the more attention it requires. The simplest example is childhood obesity in Mexico, which has an increase that confers this disease public health problem dimensions. ${ }^{29}$

- Seriousness of the final condition. It can be ordered from lowest to highest seriousness: 
- Study of surrogate characteristics that have no clinical translation. Example: saxagliptin anti-inflammatory effects in patients with type 2 diabetes mellitus. ${ }^{30}$

- Study of characteristics inherent to a disease without clinical manifestations or consequences. Example: study on the efficacy of alogliptin versus glipizide in diabetic patients treated with metformin, where the goal is the control of blood glucose without clinical outcomes being explored. ${ }^{31}$

- Study of clinical manifestations of disease or minor, generally reversible, complications, which do not imply risk for life. Example: meta-analysis to assess the effect of canaglifozin on glycosylated hemoglobin, with benefits in weight and blood pressure. ${ }^{32}$

- Study of major or irreversible complications of a disease that can be life-threatening. Example: a cohort of pediatric cancer survivors who received chemotherapy shows the presence of treatment-associated deafness. ${ }^{33}$

- Study related to short or mid-term mortality (five ensuing years) or disabling sequelae. Example: study of premature newborns with the purpose to identify those with higher probability of death or grade IV intraventricular hemorrhage. ${ }^{34}$

- Other important characteristics for the same clinical outcome:

- Economic cost studies. Direct cost for the disease or for treatment, such as hospitalization cost, ${ }^{35}$ and indirect cost, among others, by making it impossible to carry out daily activities. Example: indirect costs attributed to type 2 diabetes mellitus complications, e.g. retinopathy USD $\$ 10,323,421$, cardiovascular disease USD $\$ 12,843,134$, nephropathy USD $\$ 81,814,501$, neuropathy USD $\$ 2,760,271$, peripheral vascular disease USD $\$ 2,042,601 .{ }^{36}$

- Cost reduction. Even with the same success and adverse events, there can be cost reduction due to price or treatment days' reductions. Example: a study was conducted on the performance of clinical data and rapid tests for the diagnosis of influenza. Although the use of rapid tests represents an extra cost in the initial care of patients with suspected influenza, they were found to ultimately decrease the costs due to timely diagnosis. ${ }^{37}$

- Treatment simplification. This characteristic will always impact on adherence to the maneuver with a consequent increase in success. Example: one study demonstrated that a pediatric population with community-acquired pneumonia that had once-daily antibiotic dosing showed higher adherence, lower hospitalization rates and higher rates of cure than a population in which a three-dose antibiotic was used. ${ }^{38}$

- Adverse events assessment. Every maneuver has adverse events. Although we are used to observing them in experimental maneuvers, they should also be considered in non-experimental (observational) maneuvers. Example: in the ACCORD trial, the effect of intensive glucose control was assessed in diabetic patients. The result was that intensive glucose control did not decrease mortality associated with acute myocardial infarction ( $\mathrm{HR}=0.97,95$ $\% \mathrm{Cl}=0.70-1.36$ ), but the percentage of patients with severe hypoglycemic events did increase from 6.94 to $21.6 . \%(p<0.03){ }^{39}$

- Balance of benefits versus adverse events. Every time we assess the benefit of a maneuver, we must subtract the equivalent adverse events. Example: in the SPRINT trial, which analyzed the effect of hypertension strict control in comparison with standard treatment, although cardiovascular disease was reduced by $2.1 \%$ at 3 years, kidney disease was found to increase by $3 \% .{ }^{40}$

c) Relevance of the maneuver, where the following should be considered:

- Absolute gain in the outcome by action of the maneuver-magnitude of the maneuver, with absolute risk increase or reduction-. In general, for a therapeutic maneuver, a direct gain of $10 \%$, which is equivalent to a number needed to treat of 10 , is accepted as clinically relevant. However, even smaller benefits should be considered when the maneuver is preventive, low-cost and has minimal risk, or when the outcome is serious, leaves disabling sequelae or is life-threatening. Example: in one study, communities that received intensive intervention versus occasional intervention to reduce obesity in children were compared. Although the effect was marginal $\left(1.4 \mathrm{~kg} / \mathrm{m}^{2}\right)$, the intervention was very low-cost and could impact in the long term. ${ }^{41}$

- Control of confounding or modifying variables. In order for the weighing of a maneuver real value to be feasible, the benefit attributed to it should always be considered once the modifying and confounding variables are controlled; otherwise, 
this benefit will be overestimated on numerous occasions. Example: clinical trial in obese patients with type 2 diabetes mellitus whose goal was glycemic control when comparing pharmacological treatment versus pharmacological treatment + gastric bypass or gastric band placement. At 12 months, the patients who underwent the surgical procedure reached $38 \%$ of glycemic control versus $5 \%$ in the pharmacological group, with the improvement being attributed only to the surgical maneuver, without considering weight loss during follow-up as the main confounding variable. ${ }^{42}$ Another very important example, given the impact it has represented in the measurement of global cardiovascular risk, is, within Framingham's cardiovascular risk model, the omission of cardiovascular disease history, physical activity and obesity, which has caused for the per se minimum risk represented by lipid, blood pressure, and glucose elevation, as well as smoking, to be overestimated ( 0.4 to $0.6 \%$ annually). ${ }^{43}$

- Frequency of exposure to the maneuver. Not all maneuvers are therapeutic actions assigned by the doctor as in a clinical trial; therefore, unlike this setting, where in most cases each maneuver is distributed to $50 \%$ of the population, in observational studies, exposure to the maneuver can be lower, even below $10 \%$, which has to be considered together with its impact on the outcome. Example: in a study to evaluate the association of high troponin levels with in-hospital mortality in patients with heart failure, only $6.2 \%$ of patients showed elevated levels. ${ }^{44}$

- Presence of modifiable maneuvers. It is always important to identify risk or prognostic factors, but it is of greater benefit when they are modifiable. Example: age is a non-modifiable risk factor for both osteoporosis and cardiovascular disease, unlike lifestyle, which can always be modified. ${ }^{45}$

\section{Applicability of the answer}

Since the planning and rationale of the question we have to ask ourselves about the final usefulness and applicability of the possible answer. This is known as the "latent goal". Consequently, when formulating a hypothesis, the answer and its application should be imagined. When we are not clear about the latent goal we can get lost in the way and mistake intermediate outcomes for the final outcome, by means of which often we lose sight of the applicability of results.
Example: through various publications, evidence has accumulated on mental disorders having an important etiological basis in neurodevelopment and neurobiology: ${ }^{46-48}$ however, the applicability of this knowledge for diagnostic purposes still appears distant. Similarly, the exaltation of dyslipidemia, hypertension and glucose elevation as cardiovascular risk factors has led to a large number of strategies directing their objectives to the control of these factors, and the real outcome they should target has been neglected.

\section{Conclusions}

Once the aspects of feasibility and reasonableness of the questioning generated by observation, ${ }^{15}$ lack of a previous answer, ${ }^{13,16}$ relevance of the possible response to be obtained $d^{5,17}$ and applicability are satisfactorily covered, it can be concluded that the question is "clinically relevant".

Just as in a research project the probability of reaching statistical significance $(p<0.05)$-a term that refers to the probability of the result being due to chance- is considered already since the design, it is also essential to justify if the question is "clinically relevant" from the beginning. Example: when studying the effect of statins on the reduction of cardiovascular mortality in men with dyslipidemia, a 10-year mortality of $10.3 \%$ was observed in the placebo group versus $8.6 \%$ in the group that received statins, with a relative risk reduction of $18 \%(\mathrm{HR}=0.82,95 \% \mathrm{Cl}=0.69$ $0.96, p=0.02$ ). Although the outcome was statistically significant, the magnitude of the effect of statins on mortality was only $1.7 \%$ at 10 years $(0.17 \%$ per year, number needed to treat: $f 588$ ); clearly, statistical significance is not synonymous with clinical relevance. ${ }^{6}$

Additionally, we should mention that there are measurements that, although they may represent the final outcome in some projects, must be considered in every project; an example of this is the quality control of the main maneuver or adverse events assessment. Finally, we must highlight at least a couple of ethical foundations in the rationale of the question: the responsible use of finite resources and avoiding the exploitation of research subjects. ${ }^{11}$

Obtaining an adequate answer for a question that has no clinical relevance is senseless. It should be never be forgotten that every maneuver entails adverse events, which must be subtracted from success when they are equivalent or worse than it.

It is imperative emphasizing that when a question is structured, the possible answer must be estimated. 
The purpose of clinical research is to corroborate or reject the hypothesis generated by an unsolved doubt, but based on previous information; by no means is it about "seeing what happens".

\section{References}

1. Peto R, Gray R, Collins R, Wheatley K, Hennekens C, Jamrozik K, et al. Randomised trial of prophylactic daily aspirin in British male doctors. $\mathrm{Br}$ Med J (Clin Res Ed). 1988;296:313-316.

2. Steering Committee of the Physicians' Health Study Research Group. Final report on the aspirin component of the ongoing Physicians' Health Study. N Engl J Med.1989;321:129-135.

3. The Medical Research Council's General Practice Research Framework Thrombosis prevention trial: randomised trial of low-intensity oral anticoagulation with warfarin and low-dose aspirin in the primary prevention of ischaemic heart disease in men at increased risk. Lancet. 1998;351:233-241.

4. Action to Control Cardiovascular Risk in Diabetes Study Group, Gerstein HC, Miller ME, Byington RP, Goff DC, Bigger JT, et al. Effects of intensive glucose lowering in type 2 diabetes. $N$ Engl $\mathrm{J}$ Med. 2008;358:2545-2559.

5. Emanuel EJ, Wendler D, Grady C. What makes clinical research ethical? JAMA. 2000;283:2701-2711.

6. Ridker PM, Danielson E, Fonseca FA, Genest J, Gotto AM, Kastelein JJ et al. Rosuvastatin to prevent vascular events in men and women with elevated C-reactive protein. N Engl J Med. 2008;359:2195-2207.

7. Buckley LF, Dixon DL, Wohlford GF, Wijesinghe DS, Baker WL, Van-Tassell BW. Intensive versus standard blood pressure control in SPRINT-Eligible Participants of ACCORD-BP. Diabetes Care. 2017;40:1733-1738.

8. Mi MY, Mukamal KJ. Comment on Buckley et al. Intensive versus standard blood pressure control in SPRINT-Eligible Participants of AC CORD-BP. Diabetes Care 2017:40:1733-1738. Diabetes Care. 2018; 41:e84-e85.

9. Treanor JJ, Hayden FG, Vrooman PS, Barbarash R, Bettis R, Riff D, et al. Efficacy and safety of the oral neuraminidase inhibitor oseltamivi in treating acute influenza: a randomized controlled trial. US Oral Neuraminidase Study Group. JAMA. 2000;283:1016-1024

10. Talavera JO. Investigación clínica I. Diseños de investigación. Rev Med Inst Mex Seguro Soc. 2011:49:53-58

11. Pérez-Rodríguez M, Palacios-Cruz L, Rivas-Ruiz R, Talavera JO. Investigación clínica XXIV. Del juicio clínico a la ética en investigación en humanos. Rev Med Inst Mex Seguro Soc. 2014:52:666-672.

12. Taveras EM, Marshall R, Sharifi M, Avalon E, Fiechtner L, Horan C, et al. Comparative effectiveness of clinical-community childhood obesity interventions: a randomized clinical trial. JAMA Pediatr. 2017:171:e171325.

13. Rivas-Ruiz R, Talavera JO. Investigación clínica VII. Búsqueda sistemática: cómo localizar artículos. Rev Med Inst Mex Seguro Soc. 2012;50:53-58.

14. Feinstein AR. The architecture of clinical research. Clin Pharmacol Therap. 1970;11.

15. Hulley SB, Cummings SR, Browner WS, Grady DG, Newman TB. Designing clinical research: an epidemiologic approach. EE. UU.: Lippincott Williams \& Wilkins; 2001

16. Talavera JO, Wacher-Rodarte NH, Rivas-Ruiz R. Investigación clínica III. Estudios de causalidad. Rev Med Inst Mex Seguro Soc. 2011;49:289-294.

17. Portney LG, Watkins MP. Foundations of clinical research. Applications to practice. EE. UU.: F.A. Davis Company; 2015.

18. Bradford-Hill A. The environment and disease: association or causation? Proc R Soc Med. 1965;58:295-300.

19. Zur-Hausen H. Papillomaviruses in the causation of human cancers a brief historical account. Virology. 2009;384:260-265.

20. Narisawa-Saito M, Kiyono T. Basic mechanisms of high-risk human papillomavirus-induced carcinogenesis: roles of E6 and E7 proteins. Cancer Sci. 2007:98:1505-1511.

21. Milner JJ, Rebeles J, Dhungana S, Stewart DA, Summer SC, Meyers MH, et al. Obesity increases mortality and modulates the lung metabolome during pandemic $\mathrm{H} 1 \mathrm{~N} 1$ influenza virus infection in mice. J Immunol. 2015:194:4846-4859

22. Kornum JB, Nørgaard M, Dethlefsen C, Due KM, Thomsen RW, Overvad K, et al. Obesity and risk of subsequent hospitalisation with pneumonia. Eur Respir J. 2010;36:1330-1336.

23. Quinn G, Shin CH, Maguire MG, Stone RA. Myopia and ambient lighting at night. Nature. 1999;399:113-114.

24. Gwiazda J, Ong E, Held R, Thorn F. Vision: myopia and ambient night-time lighting. Nature. 2000;(404):143-144.

25. Fergusson D, Glass KC, Hutton B, Shapiro S. Randomized controlled trials of aprotinin in cardiac surgery: could clinical equipoise have stopped the bleeding? Clin Trials. 2005;2:218-229.
26. Vanderpool HY, editor. The ethics of research involving human subjects: facing the $21^{\text {st }}$ century. EE. UU.: University Publishing Group; 1996.

27. Instituto Nacional de Salud Pública. Encuesta Nacional de Salud y Nutrición de Medio Camino 2016. Informe final de resultados. México: Instituto Nacional de Salud Pública/Secretaría de Salud; 2016.

28. Bertado-Cortés B, Villamil-Osorio L, Carrera-Pineda R, Martínez-Cortés C, Guerrero-Cantera J. Características clínicas y sociodemográficas de los pacientes con esclerosis múltiple. Rev Med Inst Mex Seguro Soc. 2016:54:186-190.

29. Vásquez-Garibay EM, Miranda-Ríos L, Romero-Velarde E, Nuño-Cosío ME, Campos-Barrera L, Nápoles-Rodríguez F, et al. Desmedro, sobrepeso y obesidad durante la transición nutricia en escolares de Arandas, Jalisco, México. Rev Med Inst Mex Seguro Soc. 2018;56:6-11

30. Keller AC, Knaub LA, Miller MW, Birdsey N, Klemm DJ, Reusch JE. Saxagliptin restores vascular mitochondrial exercise response in the Goto-Kakizaki rat. J Cardiovasc Pharmacol. 2015;65(2):137-147.

31. Del Prato S, Fleck P, Wilson C, Chaudhari P. Comparison of alogliptin and glipizide for composite endpoint of glycated haemoglobin reduction, no hypoglycaemia and no weight gain in type 2 diabetes mellitus. Diabetes Obes Metab. 2016;18:623-627.

32. Kaur K, Likar N, Dang A, Kaur G. Efficacy and safety of canagliflozin among patients with type 2 diabetes mellitus: a systematic review and meta-analysis. Indian J Endocrinol Metab. 2015;19:705-721.

33. Castelán-Martínez OD, Jiménez-Méndez R, Rodríguez-Islas F, Fierro-Evans M, Vázquez-Gómez BE, Medina-Sansón A, et al. Hearing loss in Mexican children treated with cisplatin. Int J Pediatr Otorhinolaryngol. 2014;78:1456-1460

34. Rivas-Ruiz R, Guzmán-Cabañas JM, Párraga-Quiles MJ, Ruiz-González MD, Huertas-Muñoz MD, Alvarez-Marcos R, et al. Utility of the clinical risk index for babies (CRIB) as a predictor of hospital death and intraventricular hemorrhage in very low birth weight and extremely low birth weight neonates. An Pediatr (Barc). 2007;66:140-145.

35. Granados-García V, Sánchez-García S, Ramírez-Aldana R, Zúñiga-Trejo C, Espinel-Bermúdez MC. Costos por hospitalización de adultos mayores en un hospital general regional del IMSS. Rev Med Inst Mex Seguro Soc. 2018:56:S65-S70.

36. Barquera S, Campos-Nonato I, Aguilar-Salinas C, López-Ridaura R, Arredondo A, Rivera-Dommarco J. Diabetes in Mexico: cost and management of diabetes and its complications and challenges for health policy. Global Health. 2013;9:3.

37. González-Canudas J, Iglesias-Chiesa JM, Romero-Antonio Y, Chávez-Cortes C, Gay-Molina JG, Rivas-Ruiz R. Cost-effectiveness in the detection of influenza H1N1: clinical data versus rapid tests. Rev Panam Salud Publica. 2011;29:1-8.

38. Castelán-Martínez OD, Hernández-Carbajal E, Contreras-García CE, Ojeda-Luna NG, Rivas-Ruiz R. Eficacia del tratamiento ambulatorio de la neumonía adquirida en la comunidad: revisión sistemática y metaanálisis. Rev Med Inst Mex Seguro Soc. 2016;54:128-136.

39. Miller ME, Williamson JD, Gerstein HC, Byington RP, Cushman WC Ginsberg HN, et al. Effects of randomization to intensive glucose control on adverse events, cardiovascular disease, and mortality in older versus younger adults in the ACCORD Trial. Diabetes Care. 2014;37:634-643.

40. Beddhu S, Rocco MV, Toto R, Craven TE, Greene T, Bhatt U, et al. Effects of intensive systolic blood pressure control on kidney and cardiovascular outcomes in persons without kidney disease: a secondary analysis of a randomized trial. Ann Intern Med. 2017;167:375-383.

41. Woodward-Lopez G, Gosliner W, Au LE, Kao J, Webb KL, Sagatov RD, et al. Community characteristics modify the relationship between obesity prevention efforts and dietary intake in children: the Healthy Communities Study. Pediatr Obes. 2018:13:46-55.

42. Schauer PR, Bhatt DL, Kirwan JP, Wolski K, Brethauer SA Navaneethan SD, et al. Bariatric surgery versus intensive medical therapy for diabetes: 3-year outcomes. N Engl J Med. 2014;370:2002-2013.

43. Wilson PW, D'Agostino RB, Levy D, Belanger AM, Silbershatz H, Kannel WB, et al. Prediction of coronary heart disease using risk factor categories. Circulation 1998;97:1837-1847.

44. Peacock WF, De-Marco T, Fonarow GC, Diercks D, Wynne J, Apple FS, et al. Cardiac troponin and outcome in acute heart failure. N Engl J Med. 2018;358:2117-2125.

45. Rivas-Ruiz R, Clark P, Talavera JO, Huitrón G, Tamayo JA, Salmerón J. Bone speed of sound throughout lifetime assessed with quantitative ultrasound in a Mexican population. J Clin Densitom. 2015;18:68-75.

46. Herzog JI, Schmahl C. Adverse childhood experiences and the consequences on neurobiological psychosocial, and somatic conditions across the lifespan. Front Psychiatry. 2018;9:420.

47. Riglin L, Collishaw S, Thapar AK, Dalsgaard S, Langley K, Smith GD, et al. Association of genetic risk variants with attention -deficit/hyperactivity disorder trajectories in the general population. JAMA Psychiatry. 2016;73:1285-1292.

48. Gómez-Coronado N, Sethi R, Bortolasci CC, Arancini L, Berk M, Dodd S. A review of the neurobiological underpinning of comorbid substance use and mood disorders. J Affect Disord. 2018;241:388-401. 